\title{
Human activity negatively affects stone tool-using Burmese long-tailed macaques Macaca fascicularis aurea in Laem Son National Park, Thailand
}

\author{
Michael D. Gumert, Yuzuru Hamada and Suchinda Malaivijitinond
}

\begin{abstract}
Animal traditions can affect survival by improving how individuals use their environment. They are inherited through social learning and are restricted to small subpopulations. As a result, traditions are rare and their preservation needs to be considered in biodiversity conservation. We studied Burmese long-tailed macaques Macaca fascicularis aurea living on Piak Nam Yai Island in Laem Son National Park, Thailand, which maintain a rare stone tool-using tradition for processing hard-shelled invertebrate prey along the island's shores. We found the population had 192 individuals in nine groups and most individuals used stone tools. This population is under pressure from the local human community through the development of farms and release of domestic dogs Canis familiaris onto the island. The level of anthropogenic impact varied in each macaque groups' range and juvenileinfant composition varied with impact. The proportion of young was smaller in groups overlapping farms and was negatively correlated with the amount of dog activity in their range. We also found that coastal use by macaques was negatively related to living near plantations and that the dogs displaced macaques from the shores in $93 \%$ of their encounters. We conclude that human impact is negatively affecting Piak Nam Yai's macaques and are concerned this could disrupt the persistence of their stone-use tradition. we discuss the impact and the potential consequences, and we recommend better protection of coastal areas within Laem Son National Park.
\end{abstract}

Keywords Animal tradition, coastal environment, domestic dog, habitat disturbance, long-tailed macaque, Macaca fascicularis aurea, tool use, Thailand

Michael D. Gumert (Corresponding author) Division of Psychology, School of Humanities and Social Sciences, Nanyang Technological University, Singapore 637332, Singapore. E-mail gumert@ntu.edu.sg

Yuzuru Hamada Evolutionary Morphology Section, Primate Research Institute, Kyoto University, Japan

Suchinda Malaivijitnond Primate Research Unit, Department of Biology, Faculty of Science, Chulalongkorn University, Bangkok, Thailand

Received 12 October 2011. Revision requested 13 December 2011.

Accepted 7 February 2012. First published online 14 August 2013.

\section{Introduction}

nimal traditions are behavioural strategies that can A allow species to adapt to changing conditions or better utilize their environment (Bonner, 1980; Fragaszy \& Perry, 2003). Traditions begin as innovations by one or a few individuals and are then inherited through social learning mechanisms (Fragaszy \& Perry, 2003). Traditions are not species-specific patterns of behaviour; rather, their occurrence is generally limited to a few, isolated subpopulations, making their distribution fragmented and their persistence highly vulnerable to human impact (van Schaik, 2002).

Burmese long-tailed macaques Macaca fascicularis aurea maintain stone-hammering traditions along the coasts and mangroves of Thailand and Myanmar (Carpenter, 1887; Malaivijitnond et al., 2007). Their tool use is primarily a coastal foraging adaptation, as tool use is not known to occur away from coastal habitats. Consequently, conserved coastal areas are a prerequisite for maintaining these rare macaque tool traditions. Macaca fascicularis fascicularis, which is widely distributed in Indonesia and Malaysia, is categorized as Least Concern on the IUCN Red List but $M$. fascicularis aurea is categorized as Data Deficient (Ong \& Richardson, 2008).

Stone-using macaques are rare. They have a limited distribution in Thailand, in only seven locations (Malaivijitnond et al., 2007; YouTube, 2008; Gumert et al., 2009, 2010). The most observable tool use occurs at Piak Nam Yai Island, in Laem Son National Park, Ranong, and Koram Island in Khao Sam Roi Yot National Park, Prachuab Khiri Khan. Koram is highly disturbed by tourist activity but Piak Nam Yai is more pristine and less disturbed. In Myanmar stone use was reported $>120$ years ago (Carpenter, 1887) but a nationwide survey in 2004-2009 did not report any stone-using populations (San \& Hamada, 2011). However, during this survey there was no specific intent to look for tool use. In 2011 a local guide in Kawthaung claimed the behaviour still occurred in the southern parts of the Mergui Archipelago (pers. comm. to MDG), suggesting further investigation is needed.

The stone-using habits of Burmese long-tailed macaques make them part of a rare class of extant primates that exhibit customary stone-hammering traditions, which also includes western chimpanzees Pan troglodytes verus in West Africa and bearded capuchins Cebus libidinosus in Brazil (Haslam et al., 2009). Other than these few primates only sea otters Enhydra lutris regularly use stone tools, although various 
other species of primates and birds use stone tools intermittently (Shumaker et al., 2011). Animal populations that exhibit stone tool-use are rare, and consequently these traditions are vulnerable to being extinguished by human activity.

Much of the wildlife in South-east Asia is experiencing pressure caused by rapid development and high rates of deforestation (Achard et al., 2002). Forest loss has led to a risk of extinction for a large proportion of the region's biodiversity (Sodhi et al., 2004) and is also a major driver of increasing human-wildlife conflict (Woodroffe et al., 2005). Conflict with wildlife in South-east Asia now involves numerous species, including elephants Elephas maximus, tigers Panthera tigris (Nyhus \& Tilson, 2004), pigs Sus scrofa (Linkie et al., 2007), sun bears Helarctos malayanus (Fredriksson, 2005) and several primate species (particularly Macaca spp.; Linkie et al., 2007; Riley, 2007; Gumert, 2011).

Human and long-tailed macaque populations overlap substantially and this may be the most widespread humanwildlife conflict occurring in South-east Asia (Eudey, 2008; Gumert, 2011). Human-macaque conflict is causing a reduction in long-tailed macaque populations through an increase in programmes to reduce their numbers (e.g. sterilization and culling) and systematic wild capture to collect live animals for trade (Eudey, 2008; Hasan \& Feeroz, 2010; Gumert, 2011). Control programmes are the result of increasing public complaints about macaques as pests, which are ultimately the result of an increase in degree of space shared between humans and macaques (Sha et al., 2009). The activities of humans (Gumert et al., 2011) and their domesticated animals, such as dogs Canis familiaris (Anderson, 1986), put pressure on long-tailed macaques, altering their survivorship and behaviour; this is particularly problematic for small populations (Afendi et al., 2011). Furthermore, anthropogenic impacts alter the species' ecology, increasing reliance on anthropogenic food resources, and some individuals have become completely separated from natural habitats (Fuentes et al., 2005; Malaivijitnond et al., 2011). Such adjustments to anthropogenic influence can change the wild foraging strategies of macaques, and this could potentially extinguish naturally occurring traditions such as tool use.

The tool-using long-tailed macaques in Laem Son National Park are facing the potential effects of increasing human activities. We need to understand the degree of overlap of these macaques with humans and their domestic animals, how this affects their survival, and whether it will impact their rare stone-using traditions. We have observed long-tailed macaques on Piak Nam Yai since 2005 and conducted a detailed census in 2011. We identified their grouping patterns, distribution, and population size, and observed anthropogenic impacts on the island and assessed how these factors are affecting the macaques.

\section{Study area}

Laem Son National Park is a marine national park on the western seaboard of Thailand. It protects parts of the Andaman Sea and surrounding bays, islands, and coastal areas (Fig. 1). The park was established in 1983 and covers $315 \mathrm{~km}^{2}$, of which $267 \mathrm{~km}^{2}$ is open sea (Faculty of Forestry, 1987). The Park protects $60 \mathrm{~km}$ of coastline and 15 islands, with $14 \mathrm{~km}^{2}$ of its area being mangrove forest comprising predominantly Rhizophora apiculata (DNP, 2006). These mangroves are of high conservation concern and part of a protection programme under the Ramsar Convention (Royal Forest Department, 2002). Other habitats include sandy beaches, mud flats, rocky shores, tropical rainforest and coastal Casuarina equisetifolia forests (DNP, 2006).

Of the 15 islands in the Park, long-tailed macaques inhabit only Piak Nam Yai and Thao Islands. The macaques on both of these islands use stone tools, are completely wild, and flee from approaching humans (Malaivijitnond et al., 2007). We chose Piak Nam Yai for our study because the macaques and their tool use are more easily observable there.

Piak Nam Yai is a small island with an area of $1.7 \mathrm{~km}^{2}$ and $5.4 \mathrm{~km}$ of coast (Fig. 2). The island contains mountainous tropical forest interlaced with freshwater streams. The coast is predominantly rocky shore but there is a large mangrove area and a small stretch of sandy beach. Between the mangrove and beach is a lowland grass area intermixed with sparse Casuarina groves.

In December 2004 the Indian Ocean tsunami that struck Banda Aceh, Phuket, Phang Nga and other regions of Asia, India and Africa, also struck Laem Son National Park and the surrounding villages (USAID, 2005; Kendall et al., 2010). Based on local reports no one in the nearest village, Bang Ben, was killed, but most structures were demolished and numerous livestock were lost. Reconstruction occurred quickly, supported by international and Thai charities (USAID, 2005). During reconstruction in 2006 a bridge was built that leads to a pier on Piak Nam Noi Island, a small island $100 \mathrm{~m}$ from Piak Nam Yai (Fig. 2). Laem Son National Park does not restrict access to this new bridge and pier, labelling it a free access area, and thus it has become a point of free entry into the Park for the local community and visitors. This has increased access to and use of the Park.

\section{Methods}

Surveys were conducted by boat around Piak Nam Yai between 15 January and 9 June 2011. We conducted surveys on 89 days, for an average of 5 hours per day. Each survey was tracked using a global positioning system (GPS), which collected positional data every 30 seconds. Circuits of the island were always completed so that every part of the coast was surveyed. 


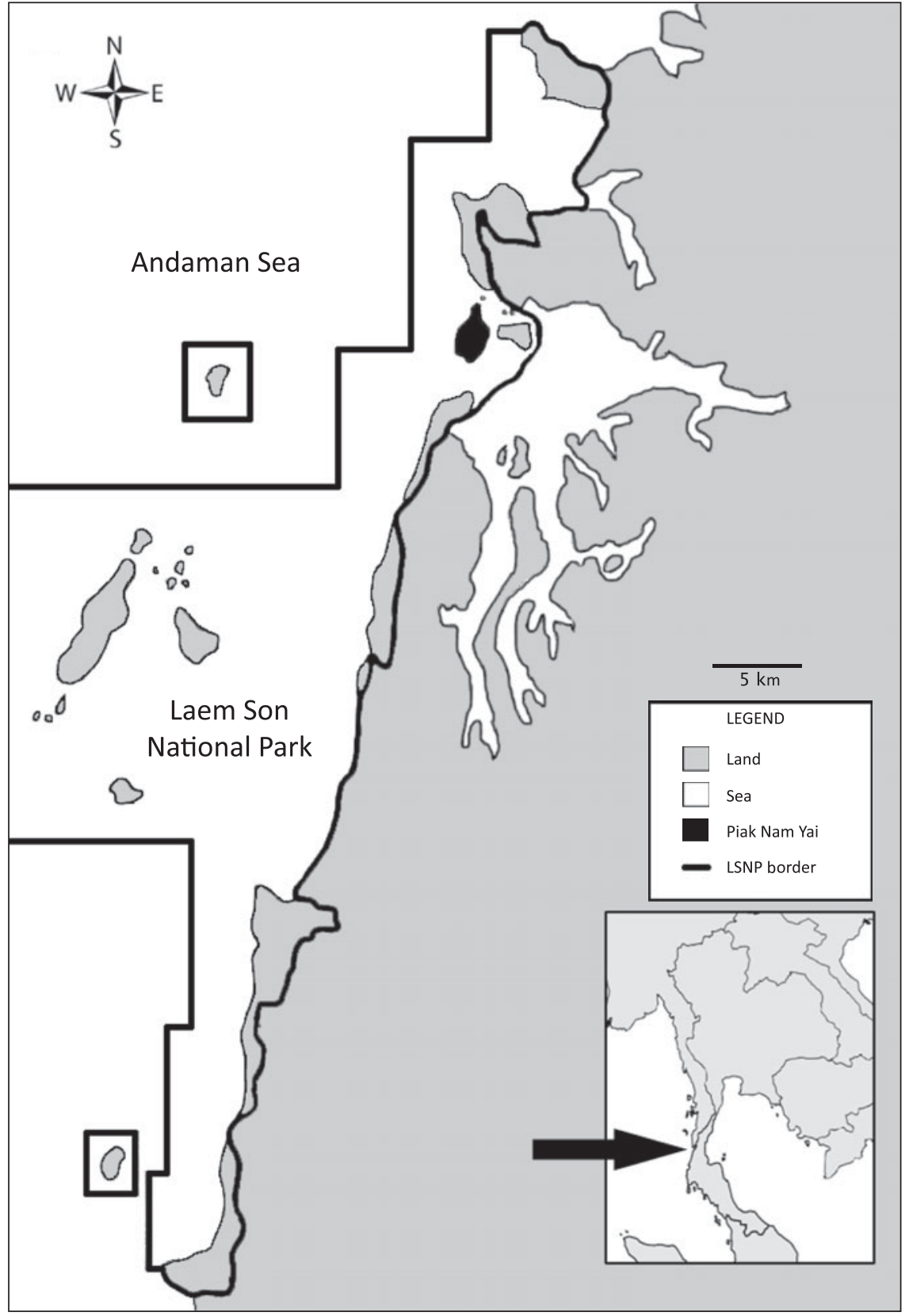

FIG. 1 Laem Son National Park (LSNP) is a marine national park along the western coast of Thailand. The study site at Piak Nam Yai Island is in black. The arrow on the inset indicates the Park's location in Thailand.
We circumnavigated the island until macaques were sighted, and then stopped and noted the position of the boat. If visible, the macaques were observed from a distance of $10-60 \mathrm{~m}$, and counted. In addition, we identified individuals using observation and photography. A macaque was considered identified after unambiguous recognition of an individual by the researcher over several days. We also recorded whether each individual was ever observed using a tool.

Identifications were used to determine groups and to count individuals. The total population was determined using the counts of identified individuals, plus estimated counts of the few unidentified individuals, which were based on head counts. The coastal range of each group was determined from the GPS data. We calculated the proportion of the population that used tools, and tested if group size was related to the length of coastal range used by groups and number of times sighted, using the Spearman rank correlation coefficient $(\rho)$. Statistics were calculated with SPSS v. 19 (SPSS Inc., Chicago, USA).

Our census method assumed that all macaques living on Piak Nam Yai must regularly come to the coast. This is a reasonable assumption. Firstly, long-tailed macaques are an edge species and reliably come to forest edges (Gumert, 2011). Secondly, macaque home ranges can be equivalent to the entire area of Piak Nam Yai (Fooden, 1995), and thus it is 


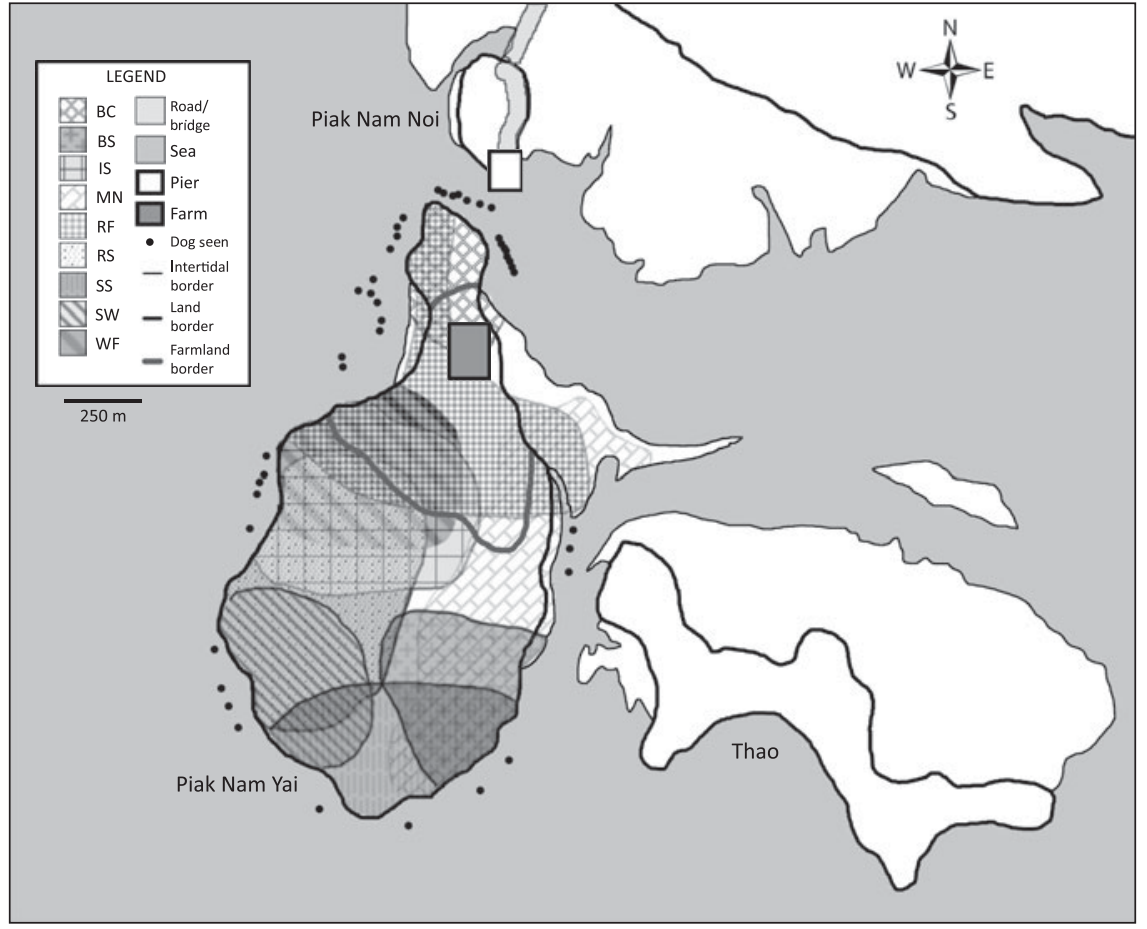

Fig. 2 Piak Nam Yai, Piak Nam Noi, and Thao Islands lie within $1.5 \mathrm{~km}$ of the mainland. The thick land border indicates shores above sea level and the thin intertidal border indicates intertidal mangroves and sandy shores. The home ranges of the nine macaque groups observed (see 2-letter codes in Table 1) are indicated, with the developing farms and infrastructure, and boat locations when dogs were sighted on the coast. unlikely a group would remain only in the interior forest. Lastly, on a small island the coast probably plays a highly important role in the macaques' diet (Gumert et al., 2009).

We recorded any types of anthropogenic impact observed on Piak Nam Yai during this study and during shorter studies conducted since 2005 (29 January2 February, 23-25 March 2005; 1-5 December 2007; 27 February-1 March, 3-23 June, 10-20 December 2008; 5-21 December 2009; 7-12 December 2011). We quantified aspects of this impact. Firstly, all groups were categorized as either having high or low overlap with human activity; high overlap was defined as $>20 \%$ of the group's range overlapping with farm plots and forest clearing. Secondly, we recorded the location of dogs, with a GPS, and recorded any dog-macaque interactions. We measured the degree to which a macaque group overlapped with dog activity by calculating a dog intensity score, using: $D I_{\mathrm{gr}}=\left(D_{\mathrm{gr}} / R_{\mathrm{gr}}\right) \times 100$, where $D$ is number of dog sightings in the range of a group, $R$ is length of coastal range of group, $g r$ is group, and DI is intensity of dog activity. This score provided a measure of dog activity that accounted for the effect of range size on the likelihood of dog-macaque encounters.

We studied the effects of anthropogenic impact on group composition and coastal usage by comparing groups that had low and high overlap with human and dog activity. We also tested the relationship between group composition and differing levels of dog activity. We used Mann-Whitney $U$ tests for the comparisons and Spearman's rank correlation coefficient to test the relationship.

\section{Results}

\section{Population census}

We made 248 circumnavigations of Piak Nam Yai over 89 days, averaging 2.79 (range 1-5) circuits per day. We sighted macaques on the coast 462 times (Table 1), averaging 1.86 sightings per circuit (range $0-6$ groups per circuit). We found that macaque sightings were almost continuously distributed along the coastal region of Piak Nam Yai (Fig. 2) except for the sandy beach and northern mangrove. Both of these zones are open areas on opposite coasts (i.e. east and west), adjacent to farming plots where people frequently work (Fig. 2). Macaques had been observed in these zones in 2007 and 2008 (MDG pers. obs.), when human activity was less frequent.

All adult and adolescent animals that came to the coastal areas were identified and logged. In June 2011 there were 143 identified individuals ( 52 adult females, 25 adult males, 12 adolescent females, 18 adolescent males, and 36 juveniles), plus a head count of 24 juveniles and 25 infants that were not individually recognizable, bringing the total population count to 192 individuals (Table 1). Observations of tool use indicated that at least $88 \%$ of the adults and adolescents, $58 \%$ of the population, used tools. The latter figure could be an underestimate because we could not reliably count tool use in unidentified juveniles.

We identified nine groups (Fig. 2). They were highly variable in size (8-35 individuals), in the length of coastline they utilized (500-1,350 m), and in the number of times we sighted them on the coast (14-116; Table 1$)$. The range of 


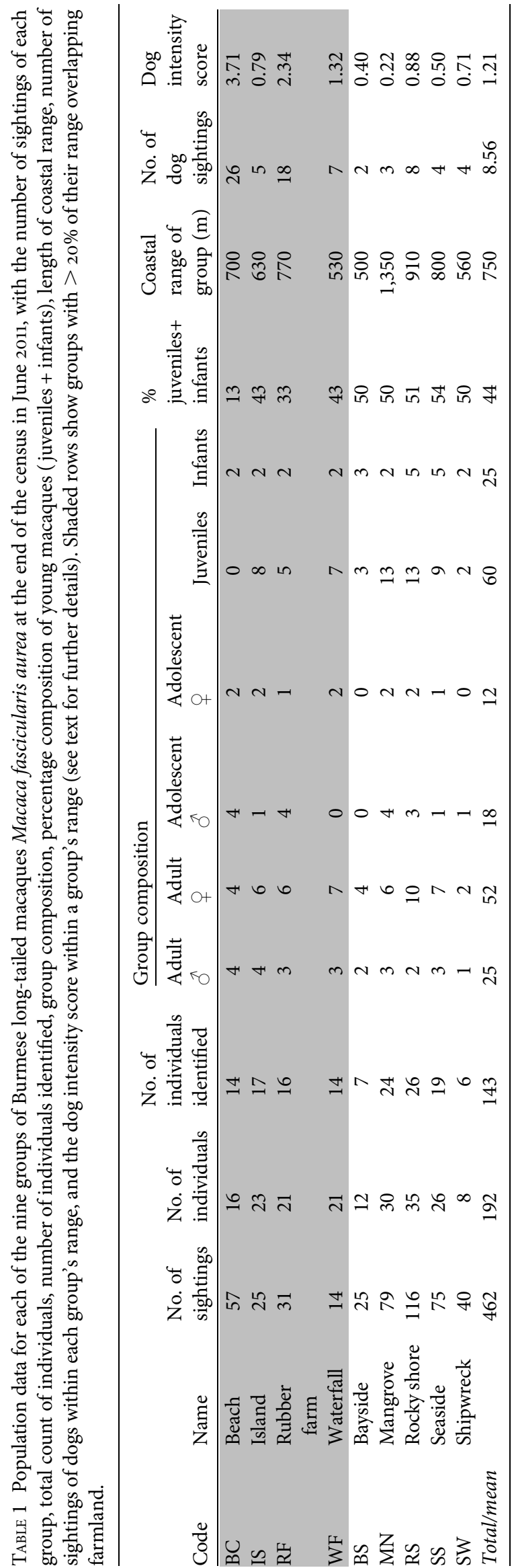

coastline a group used was highly correlated with group size $(\mathrm{n}=9, \rho=0.803, \mathrm{P}=0.009)$. There was a potentially positive but non-signficant relationship between group size and the number of times a group was sighted on the coast ( $\mathrm{n}=9, \rho=0.580, \mathrm{P}=0.102)$.

\section{Anthropogenic impacts}

After the 2004 tsunami, development occurred in many areas of Laem Son National Park, including Piak Nam Yai. Although no people yet live permanently on Piak Nam Yai, we observed an expansion of anthropogenic impact. The most significant impact has been land conversion to rubber tree Hevea brasiliensis, oil palm Elaeis guineensis, and coconut Cocos nucifera plantations on the northern part of the island (Fig. 2). The rubber and oil palm farms are particularly damaging because forest and hillsides are clearcut to plant saplings. A small day camp for plantation workers was built (Fig. 2), which consists of small houses, bungalows, a water well, and fencing. In addition, a variety of vegetable crops have been planted around the settlement.

There are several other human impacts on Piak Nam Yai. Domestic dogs were observed on the coasts, mainly near the plantations (Fig. 2). Several hundred metres of water piping were left along the eastern shores and mangroves after a failed attempt to extract fresh water from the streams during post-tsunami reconstruction. We observed collection of oysters, clams and cockles along the shores and mudflats, and high levels of net fishing around the shores. In the forests we observed opportunistic logging, metal binding of fruit trees (e.g. bitter bean Parkia speciosa) to prevent wild animals ascending, and the redirection of streams using canals. On three occasions we also found dead or injured macaques near the plantations.

To assess if human activity was affecting macaque mortality we compared the composition of juveniles and infants across groups with respect to high ( $\mathrm{n}=4$ groups) and low $(n=5)$ overlap with the farms (Table 1). High-overlap groups had significantly fewer juveniles and infants $(M=0.33, \mathrm{SD}=0.14$, range $0.13-0.43)$ than groups with low overlap $(M=0.51, \mathrm{SD}=0.02$, range $0.50-0.54$; Mann-Whitney $U$ Test: $U=0.00, \mathrm{Z}=-2.460, \mathrm{P}=0.012$; Fig. 3). High-overlap groups were potentially sighted less often on the coasts $(M=31.75$ times, $\mathrm{SD}=18.25$, range 14-57) than low-overlap groups $(M=67.00$ times, $\mathrm{SD}=35.71$, range $25-116)$ but the difference was not significant (Mann-Whitney $U$ Test: $U=3.5, Z=-1.599$, $\mathrm{P}=$ 0.110; Fig. 3).

The most obvious daily impact on the macaques was from six identified domestic dogs that we observed a total of 47 times on the shores (Fig. 2). We observed 15 dogmacaque interactions. The dogs chased macaques 13 times, passively displaced them once, and on one occasion the 


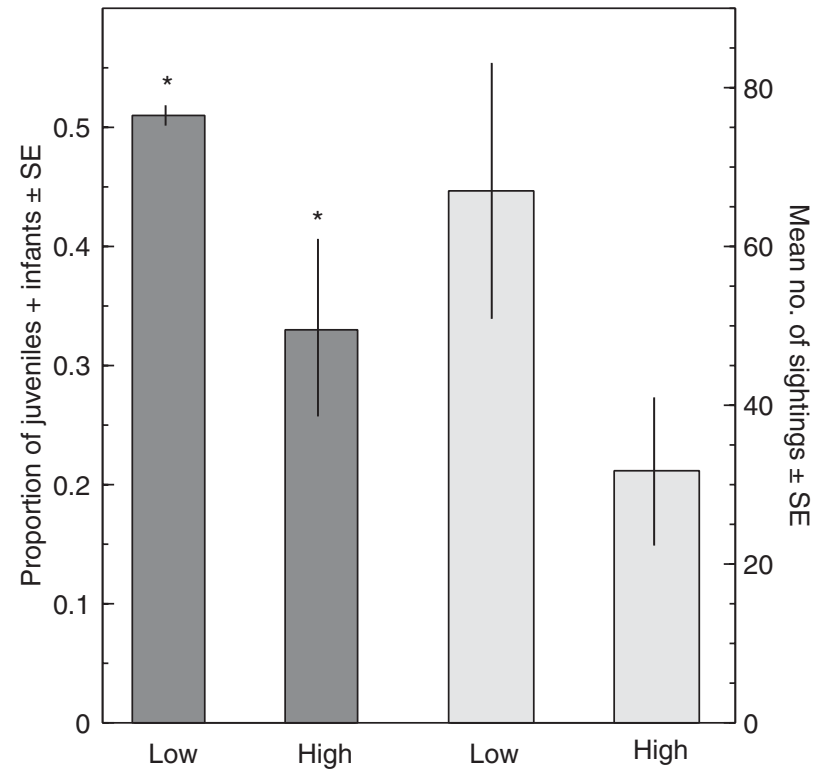

FIG. 3 Differences between groups with low and high overlap with farms in the proportion of juveniles + infants and number of sightings on the coast. Bars marked with an asterisk $\left(^{*}\right)$ are significantly different from each other.

macaques did not react as the dogs sat resting. The dogs thus displaced macaques in 14 out of 15 (93.3\%) interactions, causing them to flee and alarm call, indicating that dogs are a major deterrent for macaques using the coast.

The largest number $(n=27)$ of dog sightings occurred in the range of the northernmost group, BC (Fig. 2, Table 1). We first began to regularly observe dogs in the $\mathrm{BC}$ range in 2009 and since then we have not observed juvenile (age 1-3 years) macaques in the group. We observed at least six juveniles in the group in December 2007 and seven juveniles and three infants (age $0-1$ year) in December 2008. In December 2009 we found no infants or juveniles. In November 2010, one infant was observed but, in January 2011, it had not survived, and no juveniles or infants were observed. During our census, three infants were born into the group and one disappeared at 8 weeks of age. The other two were still surviving at the end of the census in June 2011 but were absent in December 2011.

To assess the possible impact of hunting dogs on juvenile mortality we analysed how the degree of overlap with dogs related to group composition. We calculated the intensity of dog activity in each group's range (Table 1), and then correlated each group's dog-intensity measure with juvenile-infant composition. We found a significant negative correlation between intensity of dog activity and juvenile-infant composition $(\mathrm{n}=9, \rho=-0.698, \mathrm{P}<0.037$; Fig. 4). Although we never witnessed a dog killing a macaque, the data on group composition shows that where dog-macaque overlap was highest the proportion of young macaques was much lower, suggesting predation.

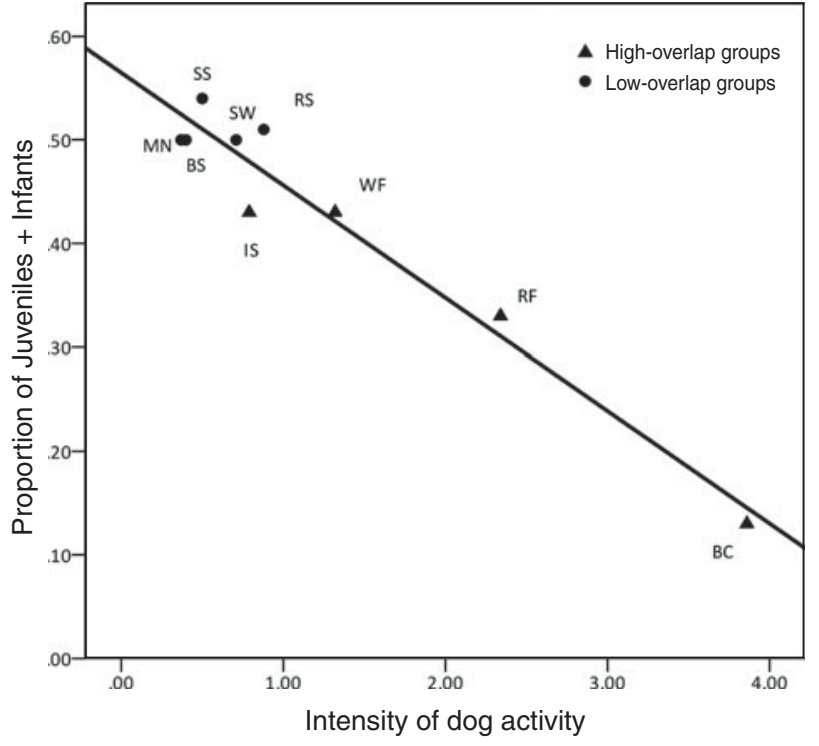

FIG. 4 The relationship between a group's juvenile-infant composition and the intensity of dog activity (for details of dog intensity score, see text) within their range. The two-lettered codes for each group are as in Table 1.

\section{Discussion}

Piak Nam Yai is a protected island in Thailand's marine national park system. It is unique because it contains the most conspicuous and regularly observable stone-tool use of any currently known wild long-tailed macaque population. There are many areas on the mainland coast near Piak Nam Yai with a similar ecology but we have not observed extensive coastal use or regular tool-based foraging by macaques there. These mainland coastal areas are surrounded by farms and roads and have been affected by regular activities of people and their domesticated animals (i.e. dogs and buffalo Bubalus bubalis). These anthropogenic influences may inhibit usage of these areas by macaques. In our study we found that human activity negatively affects tool-using macaques by limiting their usage of the coast and the proportion of young in their groups. If these impacts continue the macaque population on Piak Nam Yai could decrease, be displaced from the shores, and have their foraging strategies altered, all of which could disrupt the persistence of their stone-using tradition.

Significant anthropogenic changes in an animal's environment can alter its dietary habits, foraging strategies, and movement (Sutherland, 1998; Ditchkoff et al., 2006), and the introduction of dogs can affect habitat use through harassment and predation (Anderson, 1986; de Oliveira et al., 2008). On Piak Nam Yai human impact is altering the island's ecosystems and the foods available to macaques. Development for farmland is clearing large portions of forest, harvesting of bivalves is reducing the amount available to macaques, and dogs are repelling macaques 
from the shores and may prey on vulnerable young. If these changes continue the macaques could alter their foraging strategies, possibly limiting further development of their coastal stone-using traditions.

Cercopithecine primates, such as baboons Papio spp. (Maples et al., 1976; Altmann \& Muruthi, 1988; Hill, 2000), vervets Chlorocebus spp. (Else, 1991) and macaques (Southwick \& Siddiqi, 1994; Fuentes et al., 2005, 2007; Riley, 2007) are particularly affected by anthropogenic impacts and will significantly change their behaviour where they are affected. Their ability to adjust appears adaptive because after shifting from wild foraging patterns to synanthropy (i.e. tolerance and dependence on humans), populations of savannah baboons Papio cynocephalus (Altmann \& Muruthi, 1988), rhesus macaques Macaca mulatta (Southwick \& Siddiqi, 1977) and long-tailed macaques (Brotcorne et al., 2011) regularly rebound with population increases. This flexibility allows them to avoid local extinction and thrive in human-altered environments but at the cost of losing their wild behaviour.

Traditions are particularly vulnerable to environmental disturbances. The 'fragility of traditions' hypothesis (van Schaik, 2002) predicts that sustained disruptions from human activity can extinguish animal traditions. The threats we observed at Piak Nam Yai are continuing and have the potential to inhibit the development and crossgenerational transmission of stone-use, if not controlled. We found that young macaques have a higher mortality rate around humans and domesticated animals, and this leaves fewer developing individuals to learn traditions. Additionally, harassment by domestic dogs lessens the time macaques spend on the shores, increases their need to be vigilant, and reduces attention to learning complex toolusing patterns.

The human activities affecting macaques in Laem Son National Park are illegal according to Thailand's 1961 National Parks Act. However, ongoing legal arbitration in Thailand has confused the issue of how to regulate use of national park land (ICEM, 2003; USAID, 2011). As a result, use of protected land by local communities is common across Thailand (FAO, 2009). This issue appears to affect how Laem Son National Park is being managed because Park officials have allowed local authorities to make decisions on Park usage, which has resulted in the present conversion of land inside the Park. New management at Laem Son National Park attempted to re-establish protection in June 2011, by posting eviction notices at all plantations on Piak Nam Yai. Shortly thereafter a guard post was erected before the bridge to the free-access pier. However, these efforts were not successful and the development of the island continues.

The macaques of Laem Son National Park are an important representative population of stone-using longtailed macaques in Thailand. We recommend developing a programme to monitor and sustain the rare stone-using traditions found in some of Thailand's long-tailed macaque populations. A nationwide census needs to be conducted to examine the extent and distribution of stone tool-using macaques. Protected habitats in the coastal regions of Thailand's marine national park system should be managed so that coastal macaques can forage undisturbed. Actions to limit human impacts in protected coastal habitats would not only benefit stone-using macaques but also other species that depend on the threatened coastal ecosystems of Thailand.

\section{Acknowledgements}

The Chulalongkorn University Centenary Academic Development Project funded this study, with additional support from the Academic Research Fund of the School of Humanities and Social Sciences at Nanyang Technological University and the Ministry of Education in Singapore (Grant RGo7/95). The National Research Council of Thailand provided a Foreign Research Permit to MDG, and the National Park, Wildlife, and Plant Conservation Department of Thailand provided an entry permit for Laem Son National Park. The field methods used in this study were reviewed and approved by the NTU-Institutional Animal Care \& Use Committee in Singapore (ref: ARF SBS/ NIE-A $0138 \mathrm{AZ}$ ). We thank the park management at Laem Son National Park for their assistance, and Haromai Raksa for providing a boat service. We also thank W.C. McGrew, Martin Fisher and an anonymous reviewer for useful help and comments.

\section{References}

Achard, F., Eva, H.D., Stibig, H.J., Mayaux, P., Gallego, J., Richards, T. \& MAlingreau, J.P. (2002) Determination of deforestation rates of the world's humid tropical forests. Science, 297, 999-1002.

Afendi, N., Rachmawan, D. \& Gumert, M. (2011) The long-tailed macaques of Karimunjawa (Macaca fascicularis karimondjiwae): A small and isolated subspecies threatened by human-macaque conflict. In Monkeys on the Edge: Ecology and Management of Long-tailed Macaques and their Interface with Humans (eds M. Gumert, A. Fuentes \& L. Jones-Engel), pp. 12-14. Cambridge University Press, Cambridge, UK.

Altmann, J. \& Muruthi, P. (1988) Differences in daily life between semiprovisioned and wild-feeding baboons. American Journal of Primatology, 15, 213-221.

Anderson, J.R. (1986) Encounters between domestic dogs and free-ranging non-human primates. Applied Animal Behaviour Science, 15, 71-86.

Bonner, J.T. (1980) The Evolution of Culture in Animals. Princeton University Press, Princeton, USA.

Brotcorne, F., Wandia, I.N., Rompis, A.L.T., Soma, I.G., Suartha, I.N. \& Hunyen, M.C. (2011) Recent demographic and behavioural data of Macaca fascicularis at Padangtegal, Bali (Indonesia). In Monkeys on the Edge: Ecology and Management 
of Long-tailed Macaques and their Interface with Humans (eds M. Gumert, A. Fuentes \& L. Jones-Engel). Cambridge University Press, Cambridge, UK.

Carpenter, A. (1887) Monkeys opening oysters. Nature, 36, 53. de Oliveira, V.B., Linares, A.M., Corrêa, G.L.C. \&

Chiarello, A.G. (2008) Predation on the black capuchin monkey Cebus nigritus (Primates: Cebidae) by domestic dogs Canis lupus familiaris (Carnivora: Canidae), in the Parque Estadual Serra do Brigadeiro, Minas Gerais, Brazil. Revista Brasileira de Zoologica, $25,376-378$.

Ditchioff, S., Saalfeld, S. \& Gibson, C. (2006) Animal behaviour in urban ecosystems: modifications due to human-induced stress. Urban Ecosystems, 9, 5-12.

DNP (Department of National Parks, Wildlife and Plant Conservation) (2006) National Parks in Thailand. National Park Office, DNP, Bangkok, Thailand.

Else, J.G. (1991) Nonhuman primates as pests. In Primate Responses to Environmental Change (ed. H.O. Box), pp. 155-165. Chapman \& Hall, London, UK.

Eudey, A. (2008) The crab-eating macaque (Macaca fascicularis) widespread and rapidly declining. Primate Conservation, 23, 129-132.

Faculty of Forestry (1987) Assessment of National Parks, Wildife Sanctuaries, and Other Preserves Development in Thailand. Kasetsart University. Bangkok, Thailand.

FAO (Food and Agriculture Organization of the United Nations) (2009) Asia-Pacific Forestry Sector Outlook Study II: Thailand Forestry Outlook Study, Food and Agriculture Organization of the United Nations, Regional Office for Asia and the Pacific. FAO Regional Office for Asia and the Pacific, Bangkok, Thailand.

Fooden, J. (1995) Systematic review of Southeast Asian longtail macaques, Macaca fascicularis (Raffles, [1821]). Fieldiana: Zoology, $81,1-206$.

Fragaszy, D. \& Perry, S. (2003) The Biology of Traditions: Models and Evidence. Cambridge University Press, Cambridge, UK.

Fredriksson, G. (2005) Human-sun bear conflicts in East Kalimantan, Indonesian Borneo. Ursus, 16, 130-137.

Fuentes, A., O’Neill, N., Shaw, E. \& Cortes, J. (2007) Humans, Monkeys, and the Rock: The Anthropogenic Ecology of the Barbary Macaques in the Upper Rock Nature Reserve, Gibraltar. Almoraima: Revista de estudios Campo Gibraltareños, 35, 87-97.

Fuentes, A., Southern, M. \& Suaryana, K. (2005) Monkey forests and human landscapes: Is extensive sympatry sustainable for Homo sapiens and Macaca fascicularis on Bali? In Commensalism and Conflict: The Primate-Human Interface (ed. J. Patterson), pp. 168-195. The American Society of Primatologists Publications, Norman, USA.

Gumert, M. (2011) The common monkey of Southeast Asia: Longtailed macaque populations, ethnophoresy, and their occurrence in human environments. In Monkeys on the Edge: Ecology and Management of Long-tailed Macaques and their Interface with Humans (eds M. Gumert, A. Fuentes \& L. Jones-Engel), pp. 3-44. Cambridge University Press, Cambridge, UK.

Gumert, M., Fuentes, A., Engel, G. \& Jones-Engel, L. (2011) Future directions for research and conservation of long-tailed macaque populations. In Monkeys on the Edge: Ecology and Management of Long-tailed Macaque Populations and their Interface with Humans (eds M. Gumert, A. Fuentes \& L. Jones-Engel), pp. 328-353. Cambridge University Press, Cambridge, UK.

Gumert, M., Kluck, M. \& Malaivijitnond, S. (2009) The physical characteristics and usage patterns of stone axe and pounding hammers used by long-tailed macaques in the Andaman Sea region of Thailand. American Journal of Primatology, 71, 594-608.
Gumert, M., Low, K., Tan, V. \& Malaivijitnond, S. (2010) Sex differences, handedness, and selection preferences in the stone tool-use of Andaman long-tailed macaques (Macaca fascicularis aurea). Primate Research, 26, 112.

Hasan, M. \& Feeroz, M. (2010) Distribution and status of long-tailed macaque (Macaca fascicularis aurea I. Geofroy Saint-Hilaire, 1830) in Bangladesh. Journal of Threatened Taxa, 2, 1342-1344.

Haslam, M., Hernandez-Aguilar, A., Ling, V., Carvalho, S., de la Torre, I., Destefano, A., et al. (2009) Primate Archaeology. Nature, 460, 339-344.

Hill, C.A. (200o) Conflict of interest between people and baboons: crop raiding in Uganda. International Journal of Primatology, 21, 299-315.

iCEM (International Centre for Environmental Management) (2003) Thailand National Report on Protected Areas and Development: Review of Protected Areas and Development in the Lower Mekong River Region. ICEM, Indooroopilly, Queensland, Australia.

Kendall, M.A., Aryuthaka, C., Jittannon, C. \& Pateson, G.L.J. (2010) The tsunami in Thailand: impacts, recovery and consequences for coastal zone management. In International Symposium on Integrated Coastal Management for Marine Biodiversity in Asia. Kyoto, Japan 14-15 January 2010, pp. 10-15.

Linkie, M., Dinata, Y., Nofrianto, A. \& Leader-Williams, N. (2007) Patterns and perceptions of wildlife crop raiding in and around Kerinci Seblat National Park, Sumatra. Animal Conservation, 10, 127-135.

Malaivijitnond, S., Lekprayoon, C., Tandavanittj, N., Panha, S., Cheewatham, C. \& Hamada, Y. (2007) Stone-tool usage by Thai long-tailed macaques (Macaca fascicularis). American Journal of Primatology, 69, 227-233.

Malaivijitnond, S., Vasquez, Y. \& Hamada, Y. (2011) Human impact on long-tailed macaques in Thailand. In Monkeys on the Edge: Ecology and Management of Long-tailed Macaques and their Interface with Humans (eds M. Gumert, A. Fuentes \& L. Jones-Engel), pp. 118-158. Cambridge University Press, Cambridge, UK.

Maples, W., Maples, M.K., Greenhood, W.F. \& Walek, M.L. (1976) Adaptations of crop-raiding baboons in Kenya. American Journal of Physical Anthropology, 45, 309-315.

Nyhus, P. \& Tilson, R. (2004) Agroforestry, elephants, and tigers: balancing conservation theory and practice in human-dominated landscapes of Southeast Asia. Agriculture, Ecosystems \& Environment, 104, 87-97.

ONG, P. \& Richardson, M. (2008) Macaca fascicularis. In IUCN Red List of Threatened Species v. 2012.2. Http://www.iucnredlist.org [accessed 20 May 2013].

Riley, E. (2007) The human-macaque interface: conservation implications of current and future overlap and conflict in Lore Lindu National Park, Sulawesi, Indonesia. American Anthropologist, 109, 473-484.

Royal Forest Department (2002) Information Sheet on Ramsar Wetlands Kaper Estuary-Laemson Marine National Park-Kraburi Estuary. Http://chm-thai.onep.go.th/wetland/RIS_RAMSAR/ Kaper_Estuary.pdf [accessed 28 May 2013].

SAN, A. \& HAMADA, Y. (2011) Distribution and current status of long-tailed macaques (Macaca fascicularis aurea) in Myanmar. In Monkeys on the Edge: Ecology and Management of Long-tailed Macaques and their Interface with Humans (eds M. Gumert, A. Fuentes \& L. Jones-Engel), pp. 45-64. Cambridge University Press, Cambridge, UK.

Sha, J., Gumert, M., Lee, B., Fuentes, A., Rajathurai, S., Chan, S. \& Jones-Engel, L. (2009) Status of the long-tailed macaque 
Macaca fascicularis in Singapore and implications for management. Biodiversity and Conservation, 18, 2909-2926.

Shumaker, R., Walkup, K. \& Beck, B. (2011) Animal Tool Behavior: The Use and Manufacture of Tools by Animals. The John Hopkins University Press, Baltimore, USA.

Sodhi, N.S., Кон, L.P., Brook, B.W. \& NG, P.K.L. (2004) Southeast Asian biodiversity: an impending disaster. Trends in Ecology \& Evolution, 19, 654-660.

Southwick, C.H. \& SiddiQI, M.F. (1994) Primate commensalism: the rhesus monkey of India. Revue d'Ecologie (La Terre et la Vie), 49, 223-231.

Southwick, C.H. \& Siddiqi, M.F. (1977) Population dynamics of rhesus monkeys in northern India. In Primate Conservation (eds H.R.H. Prince Ranier III \& G.H. Bourne), pp. 339-362. Academic Press, New York, USA.

Sutherland, W. (1998) The importance of behavioural studies in conservation biology. Animal Behaviour, 56, 801-809.

USAID (US Agency For International Development) (2005) Thailand Post-Tsunami Sustainable Coastal Livelihoods Program. Coastal Resources Center, University of Rhode Island, Kingston, USA.

USAID (2011) USAID Country Profile: Property Rights and Resource Governance. Http://usaidlandtenure.net/sites/default/files/countryprofiles/full-reports/USAID_Land_Tenure_Thailand_Profile.pdf [accessed 28 May 2013].
VAN Schaik, C.P. (2002) Fragility of traditions: the disturbance hypothesis for the loss of local traditions in orangutans. International Journal of Primatology, 23, 527-538.

Woodroffe, R., Thirgood, S. \& Rabinowitz, A. (eds) (2005) People and Wildlife, Conflict or Coexistence? Cambridge University Press, Cambridge, UK.

YouTube (2008) Monkey uses a rock to open shells. Http://www. youtube.com/watch?v=LuUGBPgDICI [accessed 28 May 2013].

\section{Biographical sketches}

Michael D. Gumert studies the behaviour and ecology of Macaca fascicularis in Thailand, Singapore and Indonesia. He is interested in their social and cultural behaviour, as well as their relationship with humans and anthropogenic habitats. YUzURU HAMADA studies primate morphology and macaque population ecology across Southeast Asia. He recently completed nationwide surveys in Thailand, Laos and Myanmar. Suchinda Malaivijitnond has done surveys of macaques throughout Thailand and discovered the tool-using longtailed macaque population at Laem Son National Park. She is currently leading development of Thailand's Primate Research Institute. Her research programme involves collaboration with international scientists and the Institute is a national centre for primate field studies in Thailand. 